\section{Effect of a phenolic extract from olive vegetation water on fresh salmon steak quality during storage}

\author{
Dino Miraglia, ${ }^{1}$ Sonia Esposto, ${ }^{2}$ \\ Raffaella Branciari, ${ }^{1}$ Stefania Urbani, \\ Maurizio Servili, ${ }^{2}$ Simona Perucci, ${ }^{3}$ \\ David Ranucci'
}

'Department of Veterinary Medicine, University of Perugia, Perugia;

2Department of Agricultural, Food and Environmental Sciences, University of

Perugia, Perugia; ${ }^{3}$ Circeo Pesca S.r.l., San

Mariano-Corciano (PG), Italy

\begin{abstract}
This study aimed to evaluate the antioxidant and antimicrobial effects of a phenolic extract from olive vegetation water on fresh salmon steaks stored at $4^{\circ} \mathrm{C}$ under modified atmosphere. Twenty-four salmon steaks were respectively immersed in solutions of the diluted phenolic extract at $1.5 \mathrm{~g} / \mathrm{L}(\mathrm{A}), 3 \mathrm{~g} / \mathrm{L}$ (B), and water only as a control (CTR), packaged within a protective atmosphere (70\% carbon dioxide, $25 \%$ nitrogen and $5 \%$ oxygen) and then stored at $4{ }^{\circ} \mathrm{C}$ After $2 \mathrm{~h}$, and 3 and 6 days of storage, the fish samples were analysed for the total viable count, Enterobacteriaceae count, $\mathrm{pH}$, colour (CIE $\mathrm{L}^{*} \mathrm{a}^{*} \mathrm{~b}^{*}$ colour system), phenolic composition, $\alpha$ tocopherol content, antioxidant activity by 2,2 diphenyl-1-picrylhydrazyl (DPPH') assay, and thiobarbituric reactive substances (TBARS). A 3 $\mathrm{g} / \mathrm{L}$ phenolic extract contributed positively to the hygienic quality of the salmon by reducing the microbial growth during storage. The treated samples were slightly yellower than the CTR but only at the beginning of storage. The flesh contained $6.2 \%$ of the total polyphenols present in the initial solutions, with various percentages of the single fractions. After 6 days storage, the $\alpha$ tocopherol content in the CTR and A samples was statistically lower than the B group that also showed the lowest DPPH ${ }^{\circ}$ and TBARS values. In conclusion, the phenolic extract increased the microbiological quality and antioxidant concentration and decreased the lipid oxidation of salmon steaks during storage at $4^{\circ} \mathrm{C}$ under modified atmosphere.
\end{abstract}

\section{Introduction}

Fresh fish is highly perishable due to the presence of non-protein nitrogenous substances, lipid composition, $\mathrm{pH}$ and the high humidity that favours microbial growth and accelerates the biochemical reactions that cause degradation. A decrease in fish freshness is associated with sensorial alteration and development of unpleasant odours and flavours due to the accumulation of non-protein nitrogenous substances, as well as the compounds produced by enzymatic degradation of proteins and lipids (Gomez-Guillén and Montero, 2007). Also, oxidation of the tissue lipids has a strong effect on fish quality (Sikorski and Kolakowska, 1990). Glycerides, glycolipids and phospholipids are hydrolysed by lipases to free fatty acids, which then undergo further oxidation to produce low molecular weight compounds, such as aldehydes and ketones. These compounds are responsible for the off-odour and off-flavour of spoiled fish (Ashie et al., 1996). Furthermore, marine lipids are characterised by a high content of polyunsaturated fatty acids (PUFA), in particular, eicosapentaenoic acid (EPA) and docosahexaenoic acid (DHA) (Ackman, 1989) that undergo auto-oxidative degradation during storage and processing, to form volatile compounds responsible for the rancid off-flavour development (Gomez-Guillén and Montero, 2007). Deterioration arising from lipid oxidation may be decreased by the use of antioxidants directly added to the products (Shaidi and Ambigaipalan, 2015). Nowadays, natural antioxidants are preferred due to consumers becoming increasingly concerned about synthetic chemicals in foods (Lanciotti et al., 2004). Hence, there is a growing interest in identifying natural sources of antioxidants that can be used for food preservation (Peschel et al., 2006). The antioxidant properties of spices and herbs are due to their polyphenolic compounds, which minimise lipid oxidation in various foods (Maqsood et al., 2013; Jang and Xiong, 2016). Furthermore, there is an increasing interest also in polyphenols derived from by-products of the agrifood industry (Servili et al., 2015). Among these, olive mill wastewater, obtained by mechanical compression of olives during oil extraction, is characterised by a high content of polyphenols, which have been studied for their antioxidant properties (De Lucia et al., 2006; Di Benedetto et al., 2006; Servili et al., 2011). Furthermore, the use of these bioactive compounds in food resulted in growth inhibition of various bacterial strains (Pereira et al., 2006; Fasolato et al., 2015). In particular, oleuropein, hydroxytyrosol and aliphatic aldehydes present in olive products inhibited or delayed the growth rate of a range of bacteria and microfungi (Bisignano et al., 1999; Furneri et al., 2002; Battinelli et al., 2006). This study aimed to evaluate the antioxidant and antimicrobial effect of an olive vegetation water phenolic extract on fresh salmon steaks stored at $4^{\circ} \mathrm{C}$ under modified atmosphere.
Correspondence: Dino Miraglia, Department of Veterinary Medicine, University of Perugia, via San Costanzo 4, 06126 Perugia (PG), Italy. Tel: +39.075.5857932 - Fax: +39.075.5857932

E-mail: dino.miraglia@unipg.it

Key words: Olive vegetation water; Phenolic extract; Antimicrobial; Antioxidant; Salmon.

Conflict of interest: the authors declare no potential conflict of interest.

Received for publication: 15 July 2016. Revision received: 29 September 2016. Accepted for publication: 29 September 2016.

This work is licensed under a Creative Commons Attribution-NonCommercial 4.0 International License (CC BY-NC 4.0).

(C) Copyright D. Miraglia et al., 2016

Licensee PAGEPress, Italy

Italian Journal of Food Safety 2016; 5:6167

doi:10.4081/ijfs.2016.6167

\section{Materials and Methods}

The phenolic extract (PE) used for the experimentation was obtained as described by Esposto et al. (2015). The extract contained $666.4 \mathrm{mg} / \mathrm{g}$ total phenolics represented by 63.8 $\mathrm{mg} / \mathrm{g}$ of 3,4-dihydroxyphenylethanol (3,4DHPEA), $10 \mathrm{mg} / \mathrm{g}$ of $p$-hydroxyphenylethanol (p-HPEA), $23 \mathrm{mg} / \mathrm{g}$ of verbascoside, $558.2 \mathrm{mg} / \mathrm{g}$ of the dialdehydic form of elenolic acid linked with 3,4-dihydroxyphenylethanol (3,4-DHPEAEDA) and $11.4 \mathrm{mg} / \mathrm{g}$ of the dialdehydic form of elenolic acid linked with $p$-hydroxyphenylethanol ( $p$-HPEA-EDA). Seventy-two fresh salmon steaks (Salmo salar) with skin were obtained from a local fishery (Perugia, Italy). The salmon steaks were divided into three groups of 24 samples each and respectively immersed in solutions of the diluted PE at $1.5 \mathrm{~g} / \mathrm{L}(\mathrm{A}), 3 \mathrm{~g} / \mathrm{L}(\mathrm{B})$, and water only as a control (CTR). The steaks were arranged in a single layer, ensuring that all the pieces were fully immersed. After $10 \mathrm{~min}$, at $12^{\circ} \mathrm{C}$, the samples were drained on a grid for 5 minutes, deposited in pairs inside polystyrene trays (Sirap-Gema S.p.A., Italy) and packaged (average weight of $330 \mathrm{~g}$ ) under a modified atmosphere comprising 70\% carbon dioxide, $25 \%$ nitrogen and 5\% oxygen (Delta 2000; Ilapak Italia S.p.A., Italy). The samples were kept in the dark during storage at $4 \pm 1^{\circ} \mathrm{C}$, collected after $2 \mathrm{~h}$ (T0) and 3 (T1) and 6 (T2) days (shelf life of the product), and then transferred to the laboratory for analysis. 


\section{Microbiological analysis}

A portion $(25 \mathrm{~g})$ of each aseptically removed fish steak (from the upper left side of the fish steak) was placed in $225 \mathrm{~mL}$ of sterile, buffered peptone water (Oxoid, Basingstoke, UK), and homogenised in a stomacher apparatus (Stomacher 400 circulator; Seward Ltd, Norfolk, UK) at room temperature for $2 \mathrm{~min}$. Then, buffered peptone water was used to prepare serial decimal dilutions of the homogenates, which were analysed for total viable count (TVC), determined using Plate Count Agar (0xoid) incubated at $30^{\circ} \mathrm{C}$ for $48 \mathrm{~h}$ (UNI EN ISO 4833:2004; ISO, 2004b), and Enterobacteriaceae (ISO 21528-2:2004; ISO, 2004a). After counting, the mean and standard deviation were calculated and data were reported as Log colony forming units per gram of sample (CFU/g).

\section{Chemical and physical analyses}

For the evaluation of the physical and chemical characteristics of the samples the following determinations were carried out on the upper right side of fish steak.

\section{$\mathrm{pH}$}

Each fish steak was evaluated in triplicate using a pH meter equipped with an insertion electrode (Crison pH25, Crison, Barcelona, Spain).

\section{Colour}

The analysis was performed by a colourimeter (Minolta CR400; Chromameter, Osaka, Japan) using the CIE $\mathrm{L}^{*} \mathrm{a}^{*} \mathrm{~b}^{*}$ system (CIE, 1976). The measurements were performed in triplicate on the cut surface of each steak. The results were expressed as brightness ( $\mathrm{L}^{*}$ value), redness ( $a^{*}$ value) and yellowness ( $b^{*}$ value).

\section{Hydrophilic phenols extraction and evaluation}

Ten g of sample was homogenized with 50 mL methanol $80 \%+$ BHT $(20 \mathrm{mg} / \mathrm{L})+0.2 \%$ TCA 2M (three times) for $1 \mathrm{~min}$. at $7000 \mathrm{rpm}$, filtered each time, and concentrated up to a final volume of $25 \mathrm{~mL}$ (water extract). The extraction of the hydrophilic phenols was carried out by a Solid Phase Extraction (SPE) using a HF Mega BE-C18.5 g cartridge (Agilent Technologies, Santa Clara, CA, USA) after its activation with water and methanol. After that, $10 \mathrm{~mL}$ water extract were charged and eluted with $10 \mathrm{~mL}$ methanol. The eluted was completely evaporated under a nitrogen flush. The dried phenolic extracts were re-solubilised using $5 \mathrm{~mL}$ methanol that was immediately evaporated under a nitrogen flush. The analytical determination of hydrophilic phenols was carried out as follows: the dried extract was recovered with methanol $0.5 \mathrm{~mL}$ and then fil- tered by $0.22 \mu \mathrm{m}$ PVDF filters (Whatman, Clifton, NJ, USA) and then, $20 \mu \mathrm{L}$ were injected in HPLC instrument equipped and set as reported for the analytical determination of the hydrophilic phenols of PE (Selvaggini et al., 2014).

\section{$\alpha$-tocopherol}

$\alpha$-tocopherol extraction and evaluation was carried out according to Parazo et al. (1998).

\section{Antioxidant activity}

Antioxidant activity was evaluated by the DPPH` (2,2-diphenyl-1-picrylhydrazyl) assay.

\section{Lipid oxidation}

Lipid oxidation was assessed using the thiobarbituric reactive substances test (TBARS). The values were expressed as mg malondialdehyde (MDA)/kg fish muscle.

\section{Statistical determination}

The data were analysed using the StatView Software (SAS, Cary, NC, USA). ANOVA was performed using the immersion solution (CTR, A and B) and time (T0, T1 and T2) as the fixed and variable factors, respectively. Mean differences were analysed at $\mathrm{P}<0.05$ using Tukey's test.

\section{Results and Discussion}

\section{Microbiological analysis}

The microbiological data obtained from the salmon samples during storage are shown in Figure 1. Regarding the TVC, the B group showed mean values significantly lower than the CTR and the A groups, for each time interval considered. Regarding the Enterobacteriaceae count, the level of contami- nation was consistent among all three groups at T0, while after 3 and 6 days of storage, the samples treated with the highest phenolic concentration showed average values statistically lower than the CTR and A groups. The antimicrobial effect observed in this study is in accordance with previous studies, confirming that these bioactive substances shows antimicrobial activity in vitro (Fasolato et al., 2015) and when directly added to food. In particular, Medina et al. (2007) showed the inhibitory effect against Salmonella Enteritidis and Listeria monocytogenes in experimentally contaminated salad and mayonnaises. Furthermore, Fasolato et al. (2016), dipped chicken breasts in a phenolic concentrate obtained from olive vegetation water and found it decreased the Enterobacteriaceae and Pseudomonas counts. Nonetheless, when the same concentrate was sprayed onto fish surfaces, an antimicrobial effect was not observed (Fasolato et al., 2016). This could be due to the different concentrations of the bioactive compounds and the treatment used, as well as the type of microorganisms considered, showing the limitations in comparing results obtained from different literature studies.

\section{Chemical and physical analyses}

The $\mathrm{pH}$ detected in the fish steaks was between $6.22 \pm 0.12$ (A) and $6.32 \pm 0.05$ (CTR) at T0 and between $6.16 \pm 0.02$ (B) and $6.21 \pm 0.05$ (CTR) at T2. No difference in $\mathrm{pH}$ values was recorded during storage between the groups, except at $\mathrm{T} 0$ where the $\mathrm{pH}$ of the CTR group was higher than the A group $(\mathrm{P}<0.05)$ but not then B group. Despite the differences recorded at $\mathrm{T} 0$, the values were not considered relevant to the quality characteristics of the product.

The colour parameters of salmon samples during storage are shown in Figure 2. There were no significant differences in the $\mathrm{L}^{*}$ values

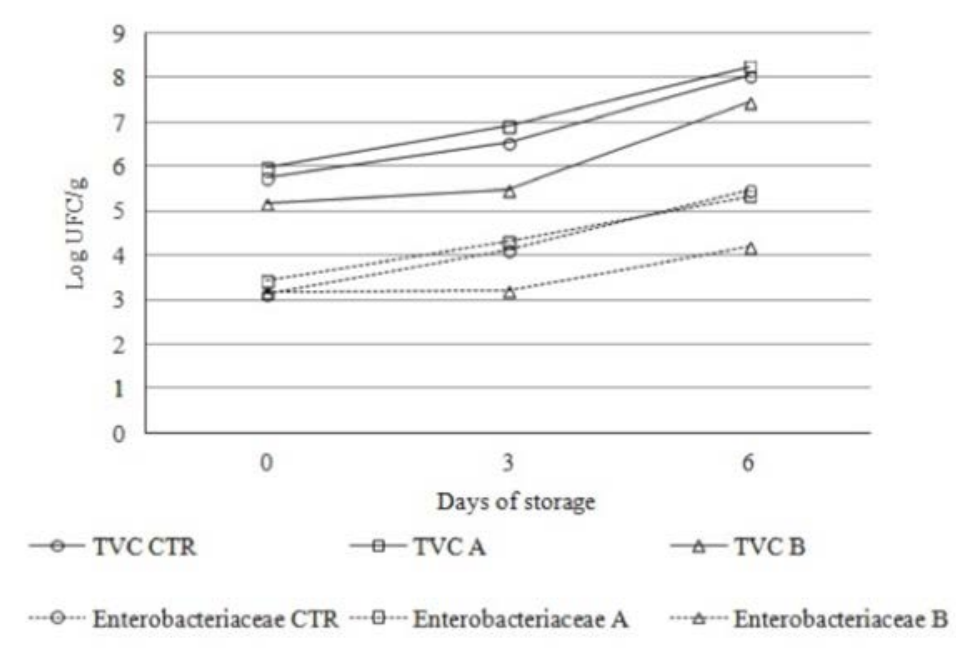

Figure 1. Microbial dynamics in salmon steaks untreated (CTR) and treated with 1.5 (A) and $3 \mathrm{~g} / \mathrm{L}(\mathrm{B})$ of phenolic extract during storage at $4^{\circ} \mathrm{C}$. TVC, total viable count. 
among the three groups, at each time considered $(\mathrm{P}>0.05)$. Similarly, the $\mathrm{a}^{*}$ values were not different between the groups $(\mathrm{P}>0.05)$, despite the values increasing significantly in all the samples after 3 days $(\mathrm{P}<0.05)$. In contrast, both the treated groups were yellower (higher $b^{*}$ value) than the CTR, but only at T0 $(\mathrm{P}<0.05)$. In fact, after 3 days of storage no difference in $b^{*}$ value was recorded among the groups, despite a significant increase in the $\mathrm{b}^{*}$ values at $\mathrm{T} 1$ and T2 $(\mathrm{P}<0.05)$. Thus, these results highlight that the polyphenols present in olive vegetation waters, altered the initial yellowness ( $\mathrm{b}^{*}$ value) of the salmon steaks. This was probably a consequence of the oxidation of the polyphenols by muscle enzymatic activity that alters the colour of the treated samples. The unique colour of salmon is an important quality value to consumers. Interestingly, an increase in both the yellowness and redness of salmon fillet during storage was reported by Erikson and Misimi (2008) and this was associated with post-mortem glycolysis. Fasolato et al. (2016) highlighted a colour change in poultry meat during storage, using sensory analyses, but no evidence was reported in fish. HPLC analysis revealed that the polyphenols concentrations of the A and B groups were vastly different at T0 (Figure 3). For both groups, 6.2\% of the total polyphenols present in the solutions had absorbed into the steaks, with a higher percentage of the absorbed polyphenols characterised as having a lower molecular weight (18.7\% of 3,4-DHPEA and $14.7 \%$ of $p$-HPEA), whereas, the higher molecular weight polyphenols, such as 3,4-DHPEA-EDA, which was the most abundant in the PE solution, only had $4.6 \%$ of its total quantity absorbed at T0. Probably, the high hydrophilic nature of this compound limited its adsorption on the salmon steaks. No traces of the polyphenols compounds were found in the CTR salmon. At the end of storage, the content of total hydrophilic polyphenols decreased by $58 \%$ and $64 \%$, in the A and B group samples, respectively. In particular, 3,4-DHPEA increased averagely by $15.5 \%$, whereas $p$-HPEA and verbascoside decreased by 25.4 and $42.0 \%$ respectively, while 3,4-DHPEA-EDA completely disappeared (Figure 3). Even if part of this compound was hydrolysed, given the increase in 3,4-DHPEA during the shelf life (Figure 3), a great quantity of it was probably involved in contrasting oxidative processes, which would otherwise have occurred in the salmon. These findings confirm those previously reported by Baldioli et al. (1996) and Esposto et al. (2014, 2015), concerning other food matrices, which emphasise the high reactivity of polyphenols with a double hydroxyl group, such as 3,4-DHPEA-EDA. The HPLC evaluation of $\alpha$-tocopherol revealed a 0.12 $\mathrm{mg} / \mathrm{kg}$ (corresponding to $32.4 \%$ ) decrease in the CTR samples after six days of storage (Figure 4). Similar decreases, not significantly different to the CTR salmon, also occurred in the A group (Figure 4 ). Only a $6.5 \%$ decrease occurred in the
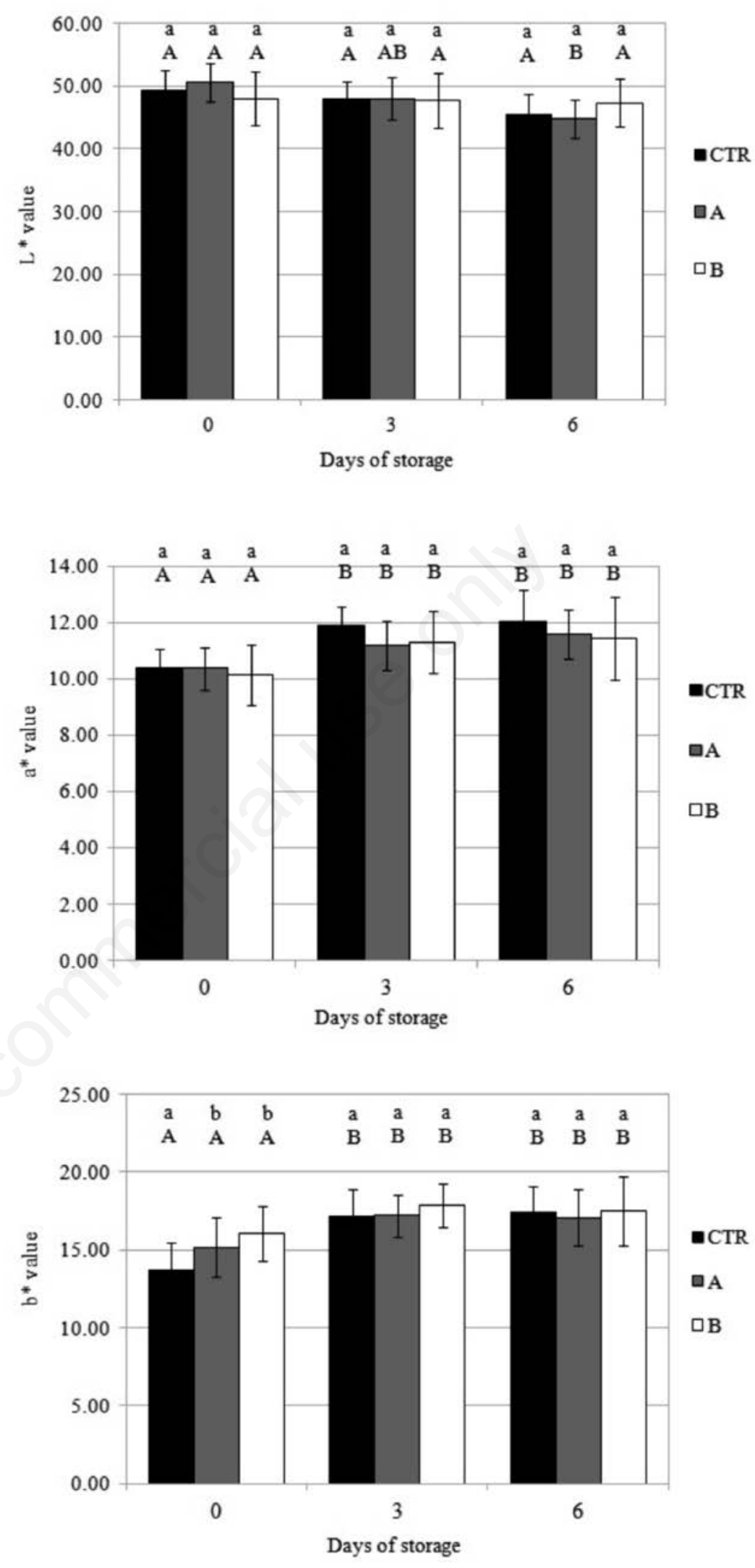

Figure 2. Colour $\left(L^{*}, a^{*}\right.$ and $\left.b^{*}\right)$ in salmon steaks untreated (CTR) and treated with phenolic extract at 1.5 (A) and $3 \mathrm{~g} / \mathrm{L}(\mathrm{B})$ during storage at $4^{\circ} \mathrm{C}$. Within each day of storage, different lowercase letters represent significant differences between groups $(P<0.05)$; within each group, different uppercase letters, represent significant differences between days of storage $(\mathbf{P}<0.05)$. 
B group after 6 days of storage, significantly lower than those registered for the other groups (Figure 4). Based on these results, it is possible that secoiridoid derivatives, like 3,4-DHPEAEDA, when present at certain concentrations, are capable of preserving other antioxidant substances, such as $\alpha$-tocopherol, from oxidative processes because of their high reactivity as primary antioxidants (Baldioli et al., 1996; Esposto et al., 2014, 2015; Servili et al., 2014). In fact, when $\alpha$-tocopherol represented the main antioxidant source (CTR group) or when the quantities of other primary antioxidants were not present at certain concentrations (A group), its substantial decrease was probably due to its involvement in decreasing oxidative damages occurring on the relative samples, during storage. The antioxidant activity during storage was evaluated, determining the minimum quantity of salmon sample (mg) required to decrease the initial concentration of the DPPH free radical $(\mathrm{mL})$ in the reaction mixture (RM) by $50 \%$ $\left(\mathrm{EC}_{50}\right)$; therefore, the data were interpreted as follows: the higher the antioxidant activity, the lower the $\mathrm{EC}_{50}$ value determined (mg of salmon/mL RM). According to this, the CTR samples had significantly lower activities than the A and B samples at T0 (Figure 5), which contained not only $\alpha$-tocopherol and other antioxidants, derived from the diet administered to the salmon (i.e. astaxanthin), but also secoiridoid derivatives from the PE. In the CTR salmon, the initial antioxidant activity completely disappeared after 3 days (Figure 5), probably because $\alpha$-tocopherol was completely involved in contrasting oxidative phenomena during the first days of the product shelf life. In treated samples, however, the $\mathrm{EC}_{50}$ value after 3 and 6 days strongly depended on the initial secoiridoids concentration because it was always significantly lower in the B group, where the highest concentration of these compounds was present (Figure 5).

Figure 6 displays the TBARS values during storage. At T0, the TBARS values showed no significant differences between the groups, while at 3 and 6 days of storage the treated samples showed lower TBARS values than the CTR sam-

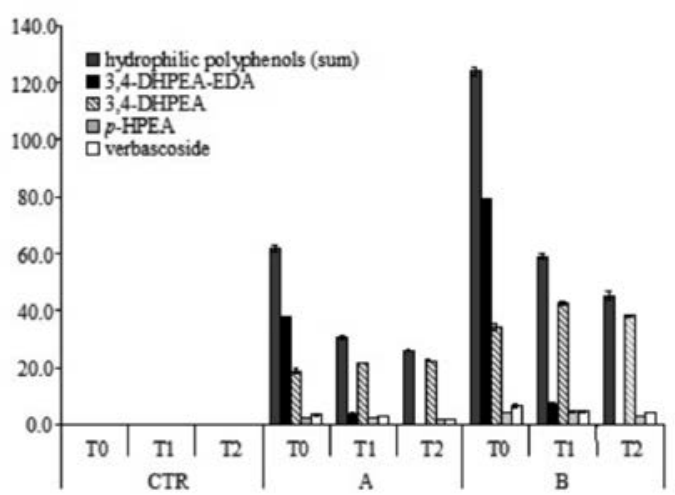

Figure 3. Hydrophilic phenols in salmon steaks untreated (CTR) and treated with phenolic extract at 1.5 (A) and $3 \mathrm{~g} / \mathrm{L}(\mathrm{B})$, after 0 (T0), 3 (T1) and 6 (T2) days of storage at $4^{\circ} \mathrm{C}$. Results expressed as the sum of 3,4-DHPEA, p-HPEA, 3,4-DHPEAEDA and verbascoside $(\mathrm{mg} / \mathrm{kg})$ and as single fractions.

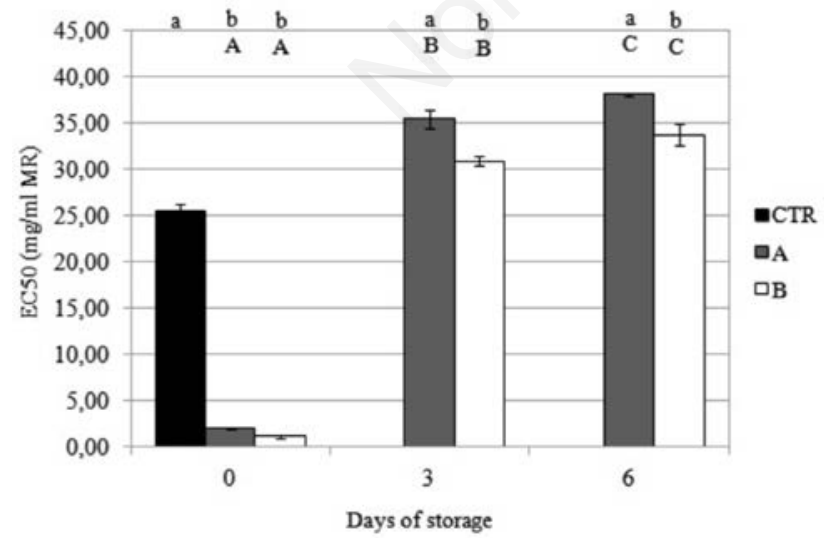

Figure 5. Antioxidant activity (DPPH ${ }^{\circ}$ assay) in salmon steaks untreated (CTR) and treated with 1.5 (A) and $3 \mathrm{~g} / \mathrm{L}$ (B) of phenolic extract during storage at $4^{\circ} \mathrm{C}$. Within each day of storage, different lowercase letters represent significant differences between groups $(P<0.05)$; within each group, different uppercase letters represent significant differences between days of storage $(\mathrm{P}<0.05)$.

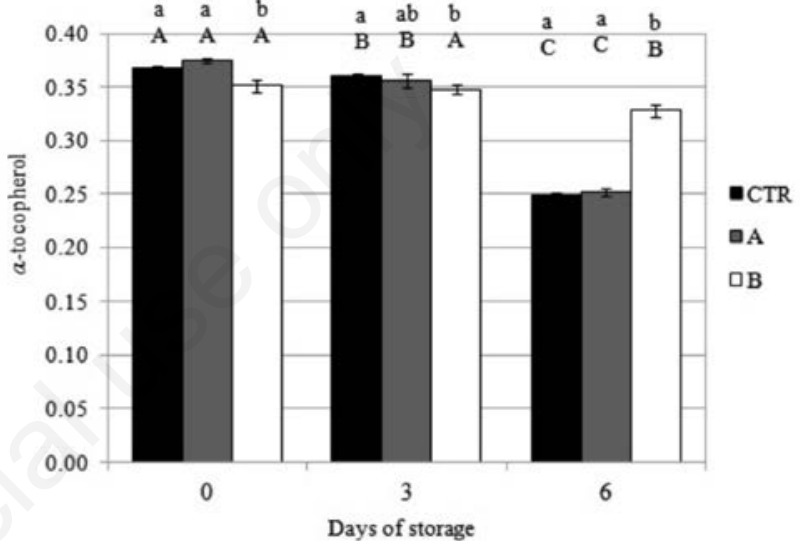

Figure 4. $\alpha$-tocopherol content $(\mathrm{mg} / \mathrm{kg})$ in salmon steaks untreated (CTR) and treated with 1.5 (A) and $3 \mathrm{~g} / \mathrm{L}$ (B) of phenolic extract during storage at $4^{\circ} \mathrm{C}$. Within each day of storage different lowercase letters represent significant differences between groups $(\mathbf{P}<\mathbf{0 . 0 5})$; within each group, different uppercase letters represent significant differences between days of storage $(\mathbf{P}<0.05)$.

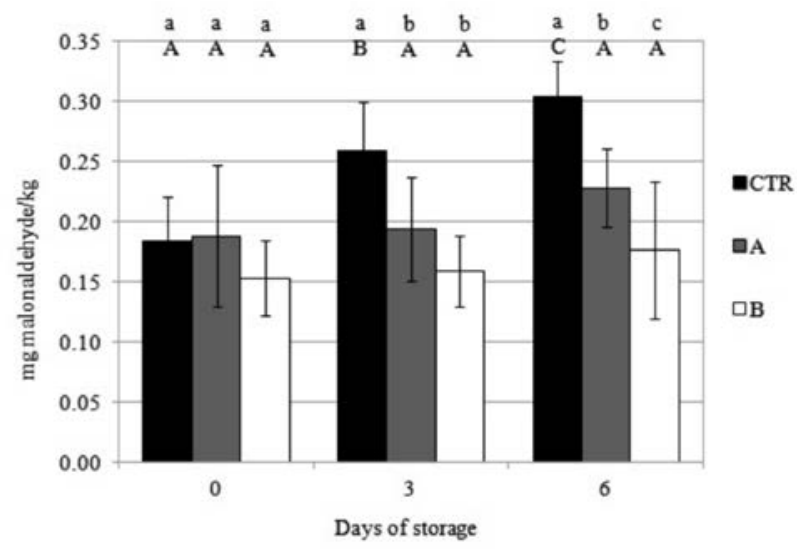

Figure 6. Thiobarbituric reactive substances in salmon steaks untreated (CTR) and treated with 1.5 (A) and $3 \mathrm{~g} / \mathrm{L}$ (B) of phenolic extract during storage at $4^{\circ} \mathrm{C}$. Within each day of storage, different lowercase letters represent significant differences between groups $(\mathrm{P}<\mathbf{0 . 0 5})$; within each group, different uppercase letters represent significant differences between days of storage $(\mathbf{P}<0.05)$. 
ples. In the CTR group, the TBARS values increased gradually $(\mathrm{P}<0.05)$ at each stage of the storage period considered, while in the $A$ and $B$ groups the values remained comparable at each time considered ( $P>0.05)$. Furthermore, at the end of the shelf life, the samples treated with the highest phenolic concentration (B group) showed the lowest TBARS level $(\mathrm{P}<0.05)$. The antioxidant effects of polyphenols derived from olive have been previously reported in both animal feeds (Branciari et al., 2015) and when directly added to products (Servili et al., 2015). Furthermore, the results concerning antioxidant effect are in agreement with Fasolato et al. (2016) that have tested a similar PE, but at a different concentration, in minced and cooked chicken breast.

\section{Conclusions}

This study demonstrated that the use of olive vegetation water phenolic extract as a natural additive can improve the quality of fresh salmon by delaying lipid oxidation, and, simultaneously, increase the antioxidant concentration. The PE also positively contributed to the hygiene quality of the salmon by decreasing the microbial level during storage, but only at the highest concentration studied. As salmon colour is one of the most important quality parameters, it is relevant to notice that possible treatment effects on colour were only detected at $\mathrm{T} 0$ and only for the yellow value. Further studies are needed to better estimate the most useful parameter, such as PE concentration, and time and treatment technique, to improve the shelf life of the products.

\section{References}

Ackman RG, 1989. Marine biogenic lipids, fats and oils. CRC Press, Boca Reton, FL, USA.

Ashie INA, Smith JP, Simpson BK, 1996. Crit Rev Food Sci Nutr 36:87-121.

Baldioli M, Servili M, Perretti G, Montedoro GF, 1996. Antioxidant activity of tocopherols and phenolic compound of virgin olive oil. J Am Oil Chem Soc 73:1589-93.

Battinelli L, Daniele C, Cristiani M, Bisignano G, Saija A, Mazzanti G, 2006. In vitro antifungal and anti-elastase activity of some aliphatic aldehydes from Oleae europaea L. fruit. Phytomedicine 13:558-63.

Bisignano G, Tomaino A, Lo Cascio R, Crisafi G, Uccelle N, Saija A, 1999. On the in-vitro antimicrobial activity of oleuropein and hydroxytyrosol. J Pharm Pharmacol 51:971-4.

Branciari R, Ranucci D, Miraglia D, Urbani S, Esposto S, Servili M, 2015. Effect of dietary treatment with olive oil by-product (olive cake) on physicochemical, sensory and microbial characteristics of beef during storage. Ital J Food Safety 4:5496.

De Lucia M, Panzella L, Pezzella A, Napolitano A, D'Ischia M, 2006. Oxidative chemistry of the natural antioxidant hydroxytyrosol: hydrogen peroxide-dependent hydroxylation and hydroxyquinone/o-quinone coupling pathways. Tetrahedron 62:1273-8.

Di Benedetto R, Varì R, Scazzocchio B, Filesi C, Santangelo C, Giovannini C, Matarrese P, D'Archivio M, Masella R, 2006. Tyrosol, the major extra virgin olive oil compound, restored intracellular antioxidant defences in spite of its weak antioxidative effectiveness. Nutr Metab Cardiovasc Dis 17:535-45.

Erikson U, Misimi E, 2008. Atlantic salmon skin and fillet color changes effected by perimortem handling stress, rigor mortis, and ice storage. Food Chem 73:50-9.

Esposto S, Taticchi A, Urbani S, Veneziani G, Sordini B, Di Maio I, Selvaggini R, Servili M, 2014. Study of the shelf-life of the virgin olive oil during its exposition to a light source. $12^{\text {th }}$ European Congress Oils, Fats and Lipids: From Lipidomics to Industrial Innovation, 2014 September 14-17, Montpellier, France, p. 430.

Esposto S, Taticchi A, Di Maio I, Urbani S, Veneziani G, Selvaggini R, Sordini B, Servili M, 2015. Effect of an olive phenolic extract on the quality of vegetable oils during frying. Food Chem 176:184-92.

Fasolato L, Cardazzo B, Balzan S, Carrao L, Taticchi A, Montemurro F, Novelli E, 2015. Minimum bactericidal concentration of phenols extracted from oil vegetation water on spoilers, starters and food-borne bacteria. Ital J Food Safety 4:4519.

Fasolato L, Cardazzo B, Balzan S, Carraro L, Andreani NA, Taticchi A, Novelli E, 2016. Application of a concentrate of phenols obtained from the vegetation water of the oil mill in the preservation of chilled food: two case studies. Ital J Food Safety 5:5651.

Furneri P M, Marino A, Saija A, Uccella N, Bisignano G, 2002. In vitro antimycoplasmal activity of oleuropein. Int $\mathrm{J}$ Antimicrob Agents 20:293-6.

Gomez-Guillén MC, Montero MP, 2007. Polyphenol uses in seafood conservation. Am J Food Technol 2:593-601.

ISO, 2004a. Microbiology of food and animal feeding stuffs. Horizontal methods for the detection and enumeration of Enterobacteriaceae. Part 2: colony-count method. ISO Norm 21528-2:2004. International Organization for Standardization, Geneva, Switzerland.

ISO, 2004b. Microbiology of food and animal feeding stuffs. Horizontal method for the enumeration of microorganisms. Colony count technique at 30 degrees C. ISO Norm 4833:2004. International Organization for Standardization, Geneva, Switzerland.

Jang J, Xiong YL, 2016. Natural antioxidants as food and feed additives to promote health benefits and quality of meat products: a review. Meat Sci 120:107-17.

Lanciotti R, Gianotti A, Patrignani F, Belletti N, Guerzoni ME, Gardini F, 2004. Use of natural aroma compounds to improve shel-flife and safety of minimally processed fruits. Trends Food Sci Technol 15:201-8.

Maqsood S, Benjakul S, Shahidi F, 2013. emerging role of phenolic compounds as natural food additives in fish and fish products. Crit Rev Food Sci Nutr 53:162-79.

Medina E, Romero C, Brenes M, de Castro A, 2007. Antimicrobial activity of olive oil, vinegar, and various beverages against foodborne pathogens. J Food Protect 70:1194-9.

Parazo MPM, Lall SP, Castell JD, Ackman RG, 1998. Distribution of $\alpha$ - and $\gamma$-tocopherols in Atlantic salmon (Salmo salar) tissues. Lipids 33:697-704.

Pereira JA, Pereira APG, Ferreira ICFR, Marcelino F, Valentão P, Andrade PB, Seabra R, Estevinho L, Bento A, Alberto Pereira J, 2006. Table olives from Portugal: phenolic compounds, antioxidant potential and antimicrobial activity. J Agr Food Chem 54:8425-31.

Peschel W, Sanchez-Rabaneda F, Diekmann W, Plescher A, Gartzia I, Jiménez D, LamuelaRaventos R, Buxaderas S, Codina C, 2006. An industrial approach in the search of natural antioxidants from vegetable and fruit wastes. Food Chem 97:137-50.

Selvaggini R, Esposto S, Taticchi A, Urbani S, Veneziani G, Di Maio I, Sordini B, Servili M, 2014. Optimization of the temperature and oxygen concentration conditions in the malaxation during the oil mechanical extraction process of four Italian olive cultivars. $\mathrm{J}$ Agr Food Chem 62:3813-22.

Servili M, Esposto S, Veneziani G, Urbani S, Taticchi A, Di Maio I, Selvaggini R, Sordini B, Montedoro GF, 2011. Improvement of bioactive phenol content in virgin olive oil with an olive-vegetation-water concentrate produced by membrane treatment. Food Chem 124:1308-15.

Servili M, Sordini B, Esposto S, Urbani S, Veneziani G, Di Maio I, Selvaggini R, Taticchi A, 2014. Biological activities of phenolic compounds of extra virgin olive oil. Antioxidants 3:1-23.

Servili M, Esposto S, Taticchi A, Urbani S, Di Maio I, Veneziani G, Selvaggini R, 2015. New approaches to virgin olive oil quality, technology, and by-products valorization. Eur J Lipid Sci Technol 117:1882-92.

Shahidi F, Ambigaipalan P, 2015. Phenolics and polyphenolics in foods, beverages and spices: antioxidant activity and health effects. A review. J Funct Food 18:820-97.

Sikorski ZE, Kolakowska A, 1990. Freezing of marine food. In: Sikorski (ed.) Resources, nutritional composition and preservation. CRC Press, Boca Raton, FL, USA. pp. 112-124. 